objects for which it was founded has increased during the past year, and the work of the Bureau of Chemical Abstracts also reflects the ever-increasing amount of investigation which is being performed in the chemical field. New decisions which will help to meet modern needs include devoting a larger number of meetings to organised discussions and summaries of recent work, offering fellowship to young chemists at half the annual subscription, selecting the papers to be read at ordinary scientific meetings, arranging that some of the endowed and special lectures shall be delivered elsewhere than in London, and appointing local representatives who will arrange lectures or discussions in collaboration with the local secretaries of other chemical organisations, and will generally promote the interests of the Society. The Council does not contemplate the establishment of local sections of the Society, since numerous local sections of the Institute of Chemistry, the Society of Chemical Industry, and of other societies are already in existence.

\section{Federation of Chemical Societies}

Prof. Henderson also referred to the new format of the Journal of the Society, and remarked : "I trust that the combined effort of the Chemical Society and the Faraday Society to produce a joint publication, which is destined to be the representative journal of British physical chemistry, will be brought to a successful issue, and that the new journal will appear next year". New conditions have created new wants, and he feels that new methods with respect to adminis. tration, to the representation of fellows in the Council, to the production and distribution of publications, and to the association of the Society with other chemical organisations must be adopted. Federation or union of at least all the principal organisations concermed with chemistry, said Prof. Henderson, is a project which is making an appeal to an increasing number of members of the profession. Prof. Henderson referred to an article on the subject in NaturE of September 24, 1932, and quoted the conclusions, saying that they well summarise the facts which compel attention to this matter. "So long as the Society remains, as now, an independent organisation," he said, "I cannot see how a larger income is to be obtained . . . and every method of reducing expenditure which can be adopted under existing conditions has been closely investigated. The same statement applies generally to the Society of Chemical Industry, the Biochemical Society, the Faraday Society, and other societies more directly interested in various branches of applied chemistry, which publish journals or abstracts or both. Consequently one is forced to the conclusion that some form of federation of these societies is not only desirable, but sooner or later inevitable. Moreover in my opinion such a federation would be incomplete and lacking in influence unless the professional organisations were also included as members."

The kind of federation which Prof. Henderson envisages would not involve material loss of individuality on the part of the members of the separate societies, for each has its special sphere of activity on behalf of the subject as a whole and of the profession generally. The final decision must rest with the members of the organisations concerned, but Prof. Henderson said he is confident that if chemists of all kinds got together in some such way as he had indicated, the effect would be altogether beneficial to the profession. He believes that the movement, if generally supported, would be welcomed by the chemical industry of the country. Sympathetic consideration must be given to the scheme to be put forward by the Federal Council for Chemistry, which has appointed a committee to frame proposals calculated to afford the chemical societies of Great Britain means of securing economies, increased efficiency, and mutual advantage.

\section{Houston Expedition over Everest}

The Houston Air Expedition to Mount Everest succeeded in its object to fly over the actual peak on the morning of April 3. The flight, starting from Lalbalu aerodrome, occupied three hours, flew about 160 miles including two circuits of the peak, reached more than $31,000 \mathrm{ft}$. altitude, and actually cleared the top by only $100 \mathrm{ft}$. The two machines, a Houston-Westland and a Westland-Wallace (Bristol Pegasus S.III engines), flew in company and carried out a concerted programme of duties. The decision to make the flight was taken on the advice of the Indian Government Meteorological Station at Purnea, which reported winds of 57 m.p.h. velocity, without undue bumpiness, at $33,000 \mathrm{ft}$. altitude, by means of the usual balloon observations. Air-Commodore Fellowes, the leader, made a preliminary reconnaissance in his Puss Moth machine before making the final decision to start.

Considerable credit is due to the crews of the Houston Expedition for their navigation, as it was impossible to adhere to the prepared scheme of observations from landmarks owing to a heavy dust haze extending up to $19,000 \mathrm{ft}$. They also met with severe down currents due to the deflection of the west wind over the mountain, causing a loss of altitude of more than $1,500 \mathrm{ft}$. in a few seconds in one case. Very good still photographs were obtained, but the results of the cinema cameras are not yet known. The automatic survey cameras were not working during part of the flight, which may mean that necessary connecting parts of the mosaic survey may be missing. In this event a further flight will be made if permission can be obtained from Nepal. The unusual clearness of the air made it difficult for the photographers to judge distances accurately. The crews were afterwards examined by the expedition's doctor, who found that they were tired, but not unduly exhausted. On April 4, a further flight was made by both machines over Kanchenjunga.

\section{Loss of the Akron}

WE much regret to record the total loss of the United States naval airship Akron, which occurred on April 4. It appears that the vessel left Lakehurst for a cruise over the coast of New England on April 3 